\title{
Impact of urban densification on building energy consumption
}

\author{
Dalong Liu ${ }^{1, *}$, Wenqin Wang ${ }^{2}$, and Hua $\mathrm{Ge}^{3}$ \\ ${ }^{1}$ College of Architecture, Xi' an University of Architecture and Technology, Xi' an, China \\ ${ }^{2}$ library, Xi' an University of Architecture and Technology, Xi' an, China \\ ${ }^{3}$ Civil \& Environmental Engineering, Concordia University, Montreal, Canada
}

\begin{abstract}
The close layout of buildings is an important cause of urban densification. It makes solar radiation and long-wave radiation being blocked, scattered, and reflected multiple times. Radiant heat is a key factor affecting building energy consumption. The formation mechanism of urban radiation field in the spaces surrounded by dense buildings was analysed. Calculation models were established for the intensity of short-wave and long-wave radiations in spaces surrounded by dense buildings. Characteristics of the radiation field in the enclosed space was analysed. Two typical cities were selected for the analysis of the impact of urban densification on building energy consumption in the hot summer and warm winter zones of China. Studies have shown that the cooling energy consumption of residential buildings in enclosed space can be reduced by $7-15 \%$ compared with open space in China's hot summer and warm winter areas. This research will lay the foundation for urban design and architectural design.
\end{abstract}

Keywords. urban densification; building layout; short-wave radiation; long-wave radiation; complex radiation field; building energy consumption

\section{Introduction}

Rapid growth of urban population in China has led to a great increase in the density of urban buildings $[1,2]$. Due to the limited space, increasing urban building density have become a necessity to accommodate the growing population. Because of the high concentration of buildings, numerous narrow, semi-closed, or fully closed spaces surrounded by dense buildings have formed in the city [3]. The long-wave and short-wave radiations in the urban enclosed space, which are shielded and reflected by various types of building facades, form a complex radiation field unlike the radiation field in an open space. What and how will the new radiation field change? How will the new radiation field affect the building energy consumption? These are some questions worth of studying.

Studies on urban radiation field formed by highdensity buildings have attracted much attention. Allegrini [4] and Bouyer [5] reported that the mutual obstructions and reflections of neighboring buildings change the intensity of solar radiation on building facade. Stromann [6] reported that an increase in urban density mutual blockage and reflection of urban buildings affects the natural lighting of buildings and acquisition of solar energy. So it changes the total energy consumption of buildings. Gao [7] simplified a calculation model for direct solar radiation, scattered, and reflected radiations on buildings. Gao analyzed the effect of radiation field on urban thermal environment by calculating the amount of solar radiation absorbed by the urban underlying surface and building surfaces. Liao [8] proposed a calculation model for solar radiation absorbed by the urban underlying surface.

Some studies had focused on the impact of changes in the radiation field caused by urban density on building energy consumption. Allegrini [4] found an increase in energy consumption in cold climates in dense urban areas (compared to rural areas) due to increased consumption of heating equipment, resulting from reduced solar availability. In Mediterranean climate, the denser context presented a slight reduction in building energy consumption when compared to a building modeled without the surrounding buildings [9]. In hot and humid climate, average reductions in the cooling load of $16-18 \%$ were observed considering the surrounding geometry and the UHI effect [10]. Allegrini [11] reported that certain parameters such as the underlying surface, material properties of surrounding building surface, and aspect ratio of street valley significantly affect the building energy consumption by comparing multiple rows of street valley and singlefamily buildings.

Yang [12] proposed the use of software ENVI-met to simulate the intensity distribution of outdoor radiation field in urban environment and analyzed its effect on building energy consumption. Xing [13] studied the thermal effects of solar radiation on urban microclimate under different underlying surface conditions such as building surface, green space, asphalt pavement, and cement brick floor. This research showed the radiation

\footnotetext{
* Corresponding author: coffeevc@xauat.edu.cn
} 
field of buildings significantly affected the urban thermal environment.

In summary, the following problems exist in the related studies. 1) There are limited studies on the impact of building enclosure on radiation field. 2) Coupled thermal effects of short-wave and long-wave radiations have rarely been studied. 3) There are no studies of the influence mechanism of radiant heat and building energy consumption. 4) There is no study on the impact of urban densification on building energy consumption for hot summer and warm winter region?

May expand to state the objective of this paper is to the impact of urban density on building energy consumption. This paper uses the enclosed spaces surrounded by dense buildings as the representative urban densification form. Firstly, The formation mechanism of complex urban radiation fields in the enclosed spaces surrounded by dense buildings is analyzed. Then the short-wave and long-wave radiation calculation models in the enclosed spaces are established. The two radiation calculation models are verified by experimental measurements. They are used as the theoretical basis for establishing the relationship between radiant heat effects and building energy consumption. Finally, using the radiation calculation model developed, the effect of radiation field on building energy consumption in a high-density built environment is analyzed by comparing the cooling energy consumption between open space and enclosed spaces.

\section{Formation mechanism of complex urban radiation field}

Dense buildings and various types of underlying surfaces form a three-dimensional urban space with special attributes. So the urban physical environment is more complicated than the open suburbs. In cities, solar shortwave direct radiation is more easily occluded, reflected, and scattered. Therefore, the short-wave radiation intensity reaching the urban surface is significantly weaker than that of the countryside. Because there are more building surfaces in cities, more radiant heat is absorbed in cities than in rural areas. So the long-wave radiation emitted by the building is also significantly increased in urban. Either short-wave or long-wave radiation in urban spaces, they both have different distribution rule than that in suburbs. The narrow space between the buildings allows the short-wave /long-wave radiation to be reflected multiple times among the building's surfaces and between the building and the ground. At the same time, the high radiation reflection coefficient of the building surface enhances the intensity of the reflected radiation. We can see that a complex radiation field of enclosed space surrounded by dense buildings in urban unlike the open space is produced, as shown in Fig. 1.

The urban complex radiation fields exist all the time. During daytime, the short-wave radiation components interact with the long-wave radiation. At night, only long-wave radiation exists. Therefore, urban radiation fields are formed differently during the day and night.
What needs to be noted is that the difference in the buildings around the space makes the radiation occlusion and reflection different, and different radiation fields are formed.
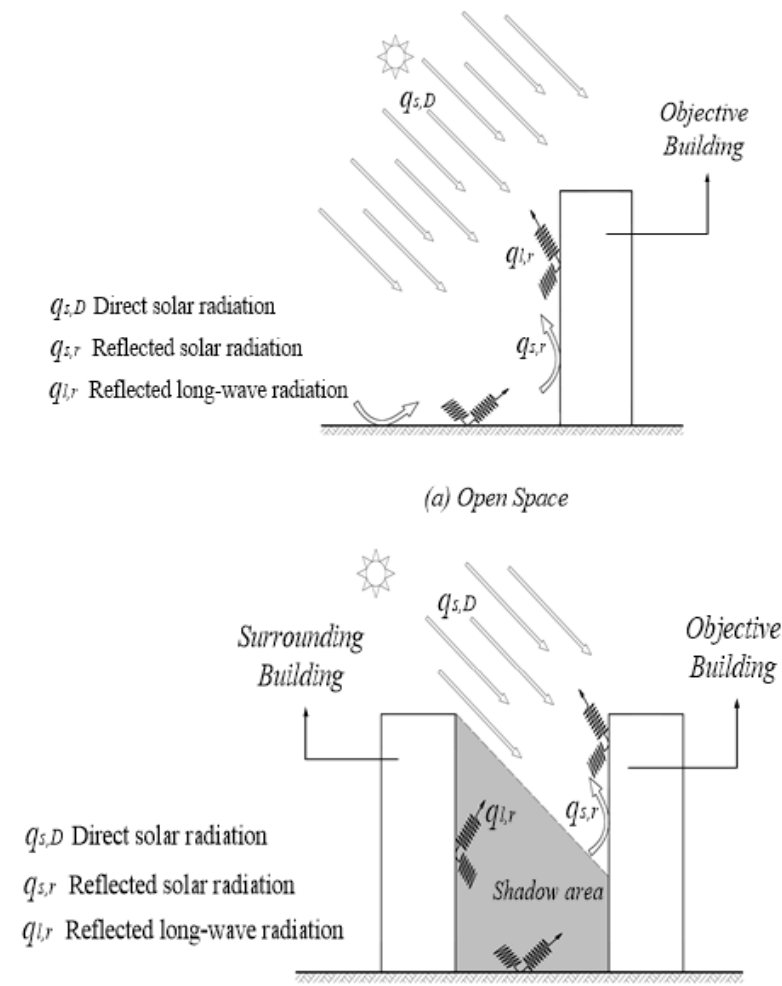

Fig. 1 Illustration of the components of radiation field

In daytime, both short-wave and long-wave radiations occur at the same time. With the change of the altitude and azimuth of the sun, different surfaces of the building receive different radiant intensities, so spatial differences in surface temperature appear on the building surface. Because of uneven temperature of each surface, the long-wave radiation emitted from building surfaces produces a difference in time and space. In time, longwave radiation emitted from building surfaces changes with the temperature of surface. In space, because different oriented building surfaces have different temperatures, the intensity of long-wave radiation varies significantly for building surfaces in different directions in enclosed space.

At night, there are no short-wave radiation, the complexity of radiation field in the enclosed space is mainly represented by the long-wave radiation. The building envelope structure stores heat from short-wave radiation during the day. Some of the heat is transmitted to the indoor. The rest is transmitted to the air by convection and the surrounding surfaces and ground through long-wave radiation. Different geometric relationships between different surfaces result in different radiation angle coefficients between surfaces. At the same time, the surface temperature of each direction of building is different. In addition, the sky absorbs long-wave radiation without reflection. Therefore, the long-wave radiation mainly exists in the semi-enclosed space formed by the building surface and 
the ground. Unlike during the day, the long-wave radiation emitted from the building surface at night has the effect of cooling the building. The stronger the intensity of the emitted long-wave radiation, the stronger the cooling effect.

Radiative heat has a significant effect on building heat transfer. Solar short-wave radiation causes buildings to absorb heat, while long-wave radiation causes buildings to dissipate heat. In traditional calculations, the surrounding environment of a building is usually calculated as an open space, i.e., the surrounding environment of exterior wall surface of a building is actually only the sky and ground. At present, most standard meteorological parameters used for energysaving calculations can provide the hourly data of these two parameters. However, for an enclosed building space in urban, the surrounding microenvironment of the target building is not only the sky and the ground, but also the surfaces of surrounding buildings.

The thermal effect of urban complex radiation fields on urban thermal environment and building energy consumption is a key issue to evaluate. This not only provides an important basis for the design of building thermal engineering, calculation, and analysis of energy conservation, but also provides an important theoretical basis for the design of green and ecological buildings.

\section{The calculation model of urban complex radiation fields}

Although the elements of the urban radiation field are complex and diverse, they can be mainly divided into short-wave radiation components and long-wave radiation components. Therefore, the calculation of urban radiation field can be divided into a short-wave radiation calculation model and a long-wave radiation calculation model.

\subsection{Calculation model of short-wave radiation}

The solar radiation incident on the facade of a building is the sum of direct solar radiation, scattered sky radiation, and reflected solar radiation. Take the south wall as an example, the formula can be expressed as follows:

$$
I_{G, s}=I_{D, s}+I_{d, s}+I_{r, s}
$$

where $I_{\mathrm{G}, \mathrm{s}}$ is the total solar radiation intensity on the surface of south wall, $\mathrm{W} / \mathrm{m}^{2} ; I_{\mathrm{D}, \mathrm{s}}$ is the direct solar radiation intensity on the surface of south wall, $\mathrm{W} / \mathrm{m}^{2}$. $\mathrm{Id}, \mathrm{s}$ is the scattered solar radiation intensity from the sky on the surface of south wall. $\mathrm{W} / \mathrm{m}^{2} . I_{\mathrm{r}, \mathrm{s}}$ is the reflected radiation intensity values obtained from the reflective surfaces of surrounding environment on the surface of south wall, $\mathrm{W} / \mathrm{m}^{2}$.

The direct radiation intensity on the building surface is related to the direct solar radiation rate of the entire surface. Then, at a certain moment in the enclosed space, the average direct solar radiation intensity on the surface of the south wall is:

$$
I_{D, s}=\frac{I_{D}}{\tan h_{\mathrm{s}}} \cdot \cos A_{\mathrm{s}} \cdot \eta
$$

where $I_{D}$ is the direct solar radiation intensity on horizontal surface, $\mathrm{W} / \mathrm{m}^{2} . \eta$ is the sun's direct radiation rate of south wall at a certain moment.

The scattered radiation intensity is related to the sky view factor of wall, and the scattered radiation intensity on south wall can be expressed as follows:

$$
I_{d, \mathrm{~s}}=I_{\mathrm{d}} \cdot S V F_{\mathrm{s}}
$$

where $I_{\mathrm{d}}$ : sky's scattered radiation intensity on the horizontal plane, $\mathrm{W} / \mathrm{m}^{2} ; S V F_{\mathrm{s}}$ : The sky view factor on the surface of south wall.

The reflected radiation intensity on the surface of south wall is the sum of short-wave radiation intensity reflected from the surrounding building surfaces and ground surface on the surface of south wall, i.e.:

$$
I_{r, s}=\left(\sum_{i} I_{\mathrm{D}, i} \cdot s \overline{W V F}_{\mathrm{s}, i}+\sum_{i} I_{\mathrm{d}, i} \cdot \overline{W V F}_{\mathrm{s}, i}\right) \cdot \rho_{i}
$$

where $I_{\mathrm{r}, \mathrm{s}}$ is the reflected radiation intensity on the surface of south wall, $\mathrm{W} / \mathrm{m}^{2} ; I_{\mathrm{D}, \mathrm{i}}$ is the direct radiation intensity on other surfaces around, $\mathrm{W} / \mathrm{m}^{2} ; I_{\mathrm{d}, \mathrm{i}}$ is the scattered radiation intensity on other surfaces around, $\mathrm{W} / \mathrm{m}^{2} ; s \overline{W V F}_{\mathrm{s}, i}$ is the sun's direct radiation, other walls face the south wall sun's direct radiation surface radiation angle coefficient; $\overline{W V F}_{\mathrm{s}, i}$ is the radiation angle coefficient of other walls for south wall sun direct surface affected by solar radiation, i.e., the visual field factors of each wall of south wall; $\rho_{i} i$ is the surface reflectivity to solar radiation.

\subsection{Calculation model of long-wave radiation}

To obtain the long-wave radiation intensity, first the temperatures of the surfaces of enclosed space should be obtained. This involves the transient heat transfer through envelope structure. Therefore, it is also necessary to combine the calculation method for onedimensional unsteady heat conduction to calculate the time-dependent temperatures of indoor and outdoor surfaces relatively efficiently. The specific calculation method is provided in the literature [14].

For the direct projected radiation component of long-wave radiation, after the radiation angle coefficient between the surfaces in an enclosed space is obtained, i.e., the average visual field factor, the direct projected radiation intensity from each surface received by a point on the wall is calculated according to the four laws of black body radiation. The projected radiation intensity can be expressed as follows:

$$
\bar{G}_{d, l s}=\sigma_{b}\left(\varepsilon_{a} T_{a}^{4} \overline{S V F}_{s}+\varepsilon_{W} T_{W}{ }^{4} \overline{W V F}_{s}+\varepsilon_{f} T_{f}{ }^{4} \overline{F V F}_{s}\right)
$$

where $\bar{G}_{d, l s}$ is the long-wave direct projection radiation intensity projected from the surrounding environment onto the surface of south wall, $\mathrm{W} / \mathrm{m}^{2} ; \overline{S V F}_{s}, \overline{W V F}_{s}$, and $\overline{F V F}_{s}$ are the average sky, wall, and ground field factors for south wall, respectively; $\varepsilon_{a}, \varepsilon_{W}$, and $\varepsilon_{f}$ are the emissivity of sky, wall, and ground, respectively; $\sigma_{\mathrm{b}}$ is 
Stefan-Boltzmann constant, $5.67 \times 10^{-8} \mathrm{~W} / \mathrm{m}^{2} \cdot \mathrm{K}^{4} ; T_{a}, T_{W}$, and $T_{f}$ are the sky, wall, and ground temperature, $\mathrm{K}$.

Many variable factors affect the complex radiation field in an enclosed space surrounded by dense buildings. This study did not consider the effect of an enclosed space on outdoor wind field. We focused on the effect of complex radiation fields on the thermal effect of buildings. From the perspective of thermal effect of a radiation field, the layout of an enclosure makes the net short-wave radiation heat gain of the building relatively smaller compared with the open space in summer. However, the enclosure between buildings decreases the wind speed in the space; this is not conducive to the ventilation and heat dissipation of building. The effect of integrated radiation field and other factors on building energy consumption in an enclosed space will be studied in the future.

\subsection{Verification of computational models}

To verify the accuracy of calculation model, enclosure spaces were found in Xi'an. The building spaces in Xi'an was shown in Fig. 2. The incomplete enclosed building space in Xi'an is formed by three oriented buildings, and the north, east, and south sides of the three buildings are equal in height with no building on the west side. The surface emissivity of wall and ground was set to 0.9 for calculation. The mean values of surface emissivity of sky in Xi'an is 0.81 .

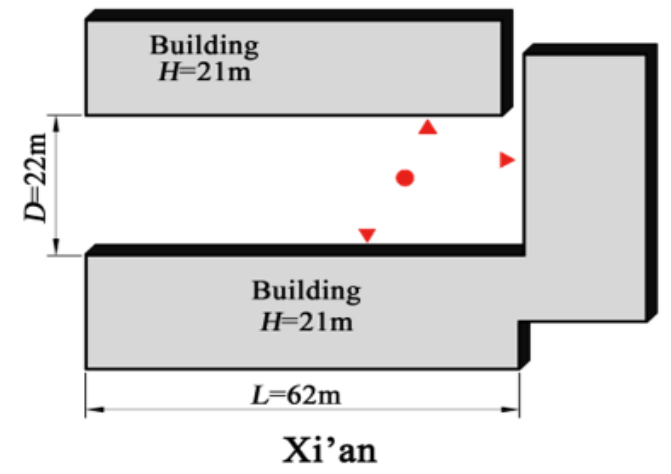

Fig. 2 test sites in Xi'an

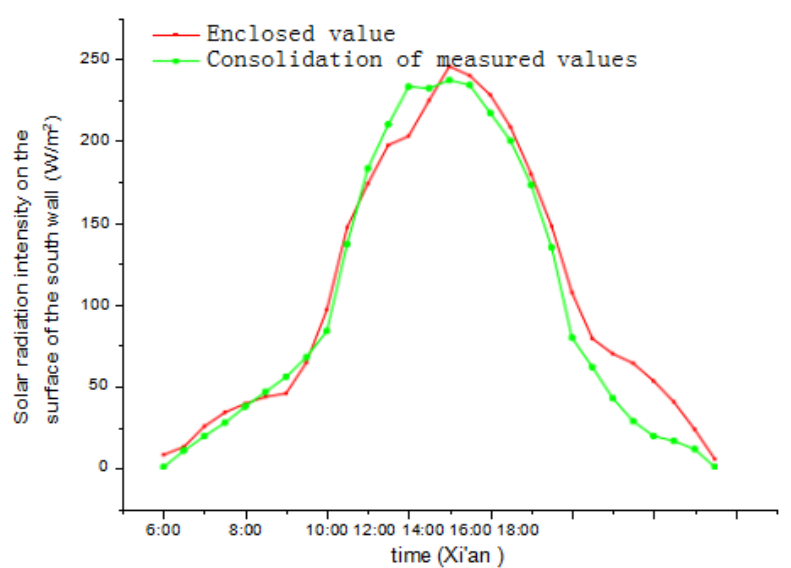

Fig. 3 calculation and test values of short-wave radiation
The intensity of short-wave and long-wave radiation received on the surface of enclosure was tested, and the measured results were compared with the calculated results. The various formulas analyzed above were compiled into Matlab software, and then the measured surface temperatures and measuring point coordinates of the site were input. The measured and calculated long-wave and short-wave radiation data are plotted in Fig. 3 and Fig. 4.

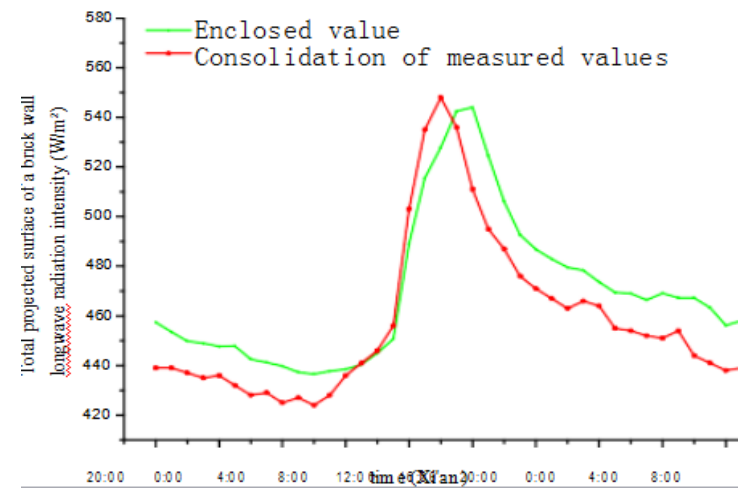

Fig. 4 calculation and test values of long-wave radiation

The relative errors between the calculated and measured values of short-wave radiation are $8.9 \%$, and the relative errors of long-wave radiation are $2.36 \%$. The theoretical calculations are consistent with the measured values and can be used to estimate the intensity of radiation field received by the outer wall of enclosed space building.

\section{Effect of complex radiation field on building energy consumption}

\subsection{The enclosed space surrounded by buildings}

To highlight the intensity distribution of radiation field in an enclosed building space of urban dense buildings, A typical enclosed space surrounded by four buildings is used as a simulation object as shown in Fig. 5-a. This degree of enclosure is the highest. The building dimension on both sides of South and North is $60 \mathrm{~m} \times 20$ $\mathrm{m} \times 24 \mathrm{~m}$. The buildings on both sides of East and West were symmetrical and had the same body volume; the size of both buildings is $22 \mathrm{~m} \times 20 \mathrm{~m} \times 24 \mathrm{~m}$. Open space refers to the space form of no other building within 100 meters of the building, as shown in Fig 5-b.

Because of the high energy consumption of air conditioning in hot summer and warm winter areas, large population in southern cities, and relatively dense buildings, two cities in Fuzhou and Guangzhou were selected as the research objects. The date of simulation was selected as July $21 \mathrm{st}$ that is the longest solar radiation in the summer solstice. The building of simulated calculation was a homogeneous wall, the thickness of building envelope was $370 \mathrm{~mm}$. The structure of the external wall meets the local requirements of building energy efficiency standards. 


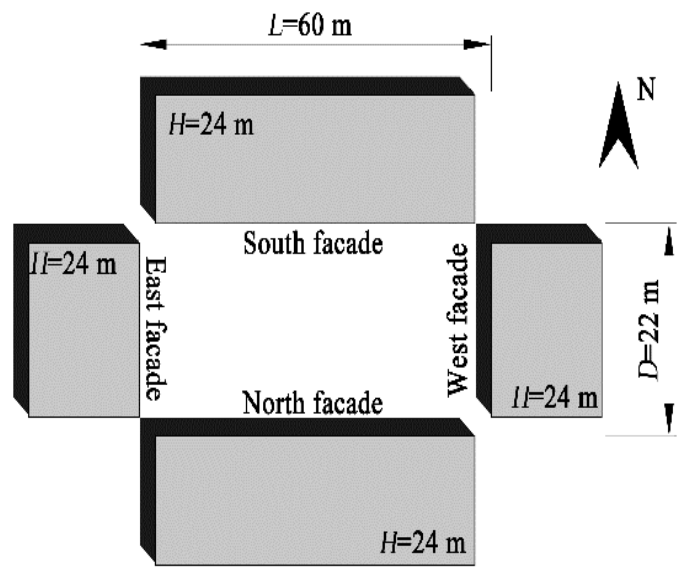

Fig. 5-a enclosed space used in simulation

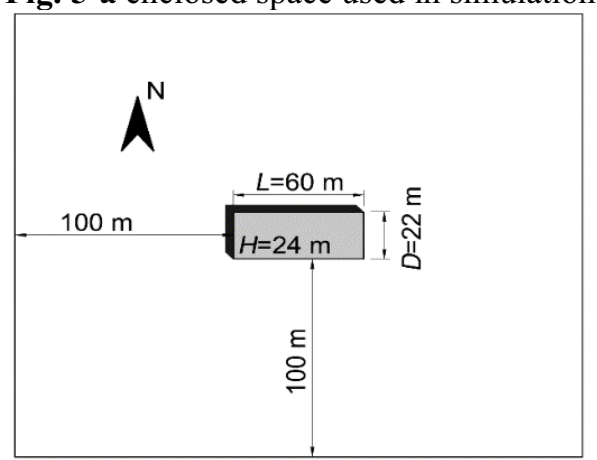

Fig. 5-b open space

\subsection{The effect on building energy consumption}

The combined thermal effect of long-wave and shortwave radiations on the exterior surface of buildings will make the net radiation flux to change the heat transfer condition of building envelope, thus forming external disturbance factors affecting the indoor thermal environment and energy consumption of building.

The influence of urban radiation field changes on building energy consumption is analyzed by calculating "the cooling energy consumption" of the envelope structure in open and enclosed urban spaces. "the cooling energy consumption", is ssentially the energy consumption of cooling energy on one wall, refers to the intensity of heat flow through a wall that faces the enclosed space under the comfortable temperature during 24 hours in a typical summer day. Of course, this heat flow is not a real building cooling energy consumpations. It is only a calculation method to analyze the influence of radiation field changes on building air conditioning energy consumption.

The one-dimensional unsteady Fourier's law is used to calculate the intensity of heat flow through the wall, and the third type of boundary conditions is used. This heat flow is applied to the cooling energy consumption of the building. The wall heat transfer is calculated on an hourly interval. The outdoor calculation temperature uses an outdoor integrated temperature as shown in $\mathrm{Eq}(6)$. In this formula, we proposed that the amount of radiation absorbed by the walls is replaced by the amount of net radiation in this study. Since longwave radiation is considered in the net radiant heat, the cooling effect of the long wave is not separately calculated in $\mathrm{Eq}(6)$.

$$
t_{s a}=t_{e}+\frac{q_{n r}}{\alpha_{e}}=t_{e}+\frac{L_{r}+G_{r}}{\alpha_{e}}
$$

where $t_{\mathrm{sa}}$ is the outdoor integrated temperature, ${ }^{\circ} \mathrm{C} ; \mathrm{t}_{\mathrm{e}}$ is the outdoor air temperature, ${ }^{\circ} \mathrm{C}$; $\mathrm{q}_{\mathrm{nr}}$ is the net radiation heat, $\mathrm{W} / \mathrm{m}^{2} ; \alpha_{e}$ is the external surface heat transfer coefficient, $19.0 \mathrm{~W} /\left(\mathrm{m}^{2} \cdot \mathrm{K}\right) ; \mathrm{L}_{\mathrm{r}}$ is the short-wave radiation heat, $\mathrm{W} / \mathrm{m}^{2}$; Gr is the long-wave radiation heat, $\mathrm{W} / \mathrm{m}^{2}$.

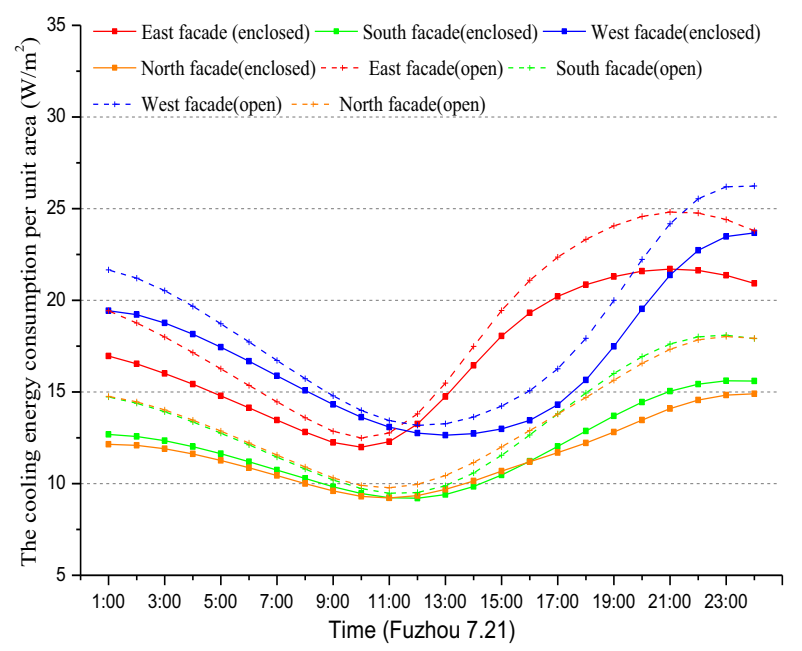

Fig. 6 cooling energy consumption on different orientations walls in Fouzhou

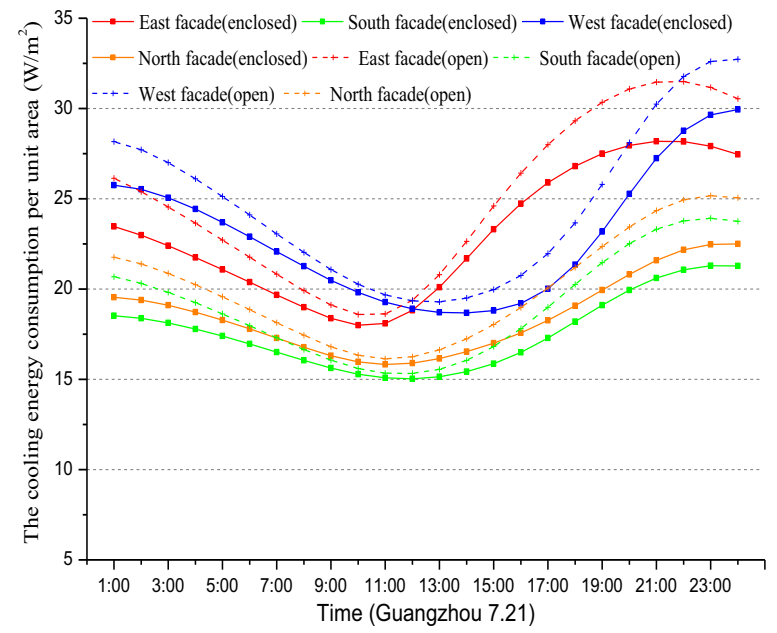

Fig. 7 cooling energy consumption on different orientations walls in Guangzhou

The curve of cooling energy consumption per unit area of envelope inner surface to maintain the indoor cooling temperature $26^{\circ} \mathrm{C}$ in the two cities was drawn, as shown in Fig. 6 and Fig.7. The cooling consumption per unit area in the open space was higher than that in the enclosed space during most of the entire day, and the differences in that between the two spaces is relatively small in the daytime. This is opposite of the trend of net radiation flux mentioned above. The main reason is the delay phenomenon of temperature wave during the heat transfer through the building envelope. 
The cooling consumption per unit area in enclosed space was lower than that in open space. The four facades and the two cities all exhibit the same pattern. The difference between cities is less than the difference in orientation. From the average data of the two cities, the north facade is most affected by the building's surround, and the least affected is the west facade. For buildings on the open spaces, enclosures can reduce the cooling load of four facades by $7-15 \%$. Therefore, in the view of radiation thermal environment, the enclosed building space layout decreased the air conditioning energy consumption of buildings compared with the open space layout. This is beneficial for building heat protection in hot summer and warm winter zones.

\section{Conclusion}

The calculation models for short-wave and long-wave radiations in urban enclosed space surrounded by buildings were constructed, and the effectiveness of the model was verified by actual measurements in Xi'an. The long-wave and short-wave radiation models were used to compare the distribution of complex radiation fields in two layout modes: open and enclosed spaces. The study showed that the short-wave radiation intensity in the enclosed space of a building is significantly smaller than that in open space, but the long-wave radiation intensity in enclosed space is obviously higher than that in open space.

A coupled thermal effect model for long-wave and short-wave radiations in an enclosed space was constructed. Taking Guangzhou and Fuzhou as examples, the effect of complex radiation fields in an enclosed space on building energy consumption was studied. The study showed that the radiation heat gain of each building envelope structure in an enclosed space is significantly smaller than the radiation heat gain in an open space in summer. Therefore, the cooling energy consumption of buildings in an enclosed space is also significantly lower $7-15 \%$ than that in open space. From the perspective of thermal effect of radiation field, the enclosure of buildings decreases the air-conditioning energy consumption of each building. Therefore, according to the distribution pattern of a complex radiation field in urban enclosed spaces, the layout of buildings can be optimized to decrease the cooling energy of buildings in summer.

\section{Acknowledgments}

This work was supported by the National Natural Science Foundation of China (Grant No. 51878536) and the Major Program of the National Natural Science Foundation of China (Grant No. 51590913)

\section{References}

\footnotetext{
Corresponding author: coffeevc@xauat.edu.cn
}

1. Pimentel D, Burgess M. World Human Population Problems [J]. Encyclopedia of the Anthropocene, 2018:313-317.

2. Liu Jia-ping. Building Physics[M]. Beijing:China Architecture \& Building Press, 2009:14-15

3. YANG Xinyan, LI Yuguo.The Impact of Building Density and Building Height Heterogeneity on Average Urban Albedo and Street Surface Temperature $[\mathrm{J}]$. Building and Environment, 2015, 90:146-156.

4. Allegrini J, Dorer V, Carmeliet J. Influence of the urban microclimate in street canyons on the energy demand for space cooling and heating of buildings[J]. Energy \& Buildings, 2012, 55:823832.

5. Bouyer J, Inard C, Musy M. Microclimatic coupling as a solution to improve building energy simulation in an urban context[J]. Energy \& Buildings, 2011, 43(7):1549-1559.

6. J. Strømann-Andersen, P.A. Sattrup. The urban canyon and building energy use: Urban density versus daylight and passive solar gains[J]. Energy \& Buildings, 2011, 43(8):2011-2020.

7. Gao Yafeng, Measurement and simulation of outdoor thermal environment for urban residential district planning[D],Chongqing university,2011.

8. Liao Xiaoqin, Study on equivalent solar radiation absorption coefficient of underlying surface in outdoor thermal environment analysis[D], South China university of technology,2013

9. A. Salvati, H. Coch, M. Morganti, Effects of urban compactness on the building energy performance in Mediterranean climate, Energy Procedia,2017, 122:499-504

10. Izabella Lima, Veridiana Scalco, Roberto Lamberts , Estimating the impact of urban densification on high-rise office building cooling loads in a hot and humid climate[J],Energy and Buildings, 2019,182(1): 30-44

11. Allegrini J, Dorer V, Carmeliet J. Impact of radiation exchange between buildings in urban street canyons on space cooling demands of buildings[J]. Energy \& Buildings, 2016, 127:1074-1084.

12. Yang Xiaoshan, A simulation method for the effects of urban microclimate on building cooling energy use[D], South China university of technology,2012.

13. Xing Yongjie; Shen Tianxing; Liu Fang, Thermal response of different earth coverings and their influence on the city thermal environment by solar radiation[J], Acta Engineering Solaris Sinica ,2002,(06):717-720

14. Bergman $\mathrm{T}$ L, Lavine A S, Incropera F P, et al. Fundamentals of Heat Transfer and Mass Trans and Mass Transfer[M].7th Edition. John Wiley\&Sons, Inc., 2011:331-333. 